\title{
Who Complies and Who Defies? Personality and Public Health Compliance
}

\author{
Julie Blais ${ }^{1 * t}$, Philip G. Chen ${ }^{2 \dagger}$ and Scott Pruysers ${ }^{3+}$ \\ ${ }^{1}$ Department of Psychology and Neuroscience, Dalhousie University, Halifax, NS, Canada, ${ }^{2}$ Department of Political Science, \\ Beloit College, Beloit, WI, United States, ${ }^{3}$ Department of Political Science, Dalhousie University, Halifax, NS, Canada
}

During the first wave of the pandemic, governments introduced public health measures in an attempt to slow the spread of the virus enough to "flatten the curve". These measures required behavioral changes among ordinary individuals for the collective good of many. We explore how personality might explain who complies with social distancing measures and who defies these directives. We also examine whether providing people with information about the expected second wave of the pandemic changes their intention to comply in the future. To do so, we draw upon a unique dataset with more than 1,700 respondents. We find honest rule-followers and careful and deliberate planners exhibit greater compliance whereas those who are entitled, callous, and antagonistic are less likely to engage in social distancing. Our experimental results show that even small differences in messaging can alter the effect of personality on compliance. For those who are more fearful and anxious, being confronted with more information about the severity of the secondwave resulted in higher levels of anticipated social distancing compliance. At the same time, we find that the same messages can have the unintended consequence of reducing social compliance among people higher in Machiavellianism.

Keywords: personality, HEXACO, dark triad, social compliance, public health messages

\section{INTRODUCTION}

In late 2019 and early 2020 the world was introduced to an outbreak of SARS-CoV-2 (COVID-19). By March 11, 2020 the rapid spread of the virus resulted in the World Health Organization (WHO) declaring it a global pandemic (World Health Organization, 2020). In the absence of a vaccine, many governments around the world introduced strict public health measures to slow the spread of the virus (Cheng et al., 2020). The terms "lockdown" and "social distancing" became part of the global vocabulary as governments closed schools, parks, and businesses, limited international travel, and mandated that individuals keep their distance from one another (working from home, restricting unnecessary travel, staying six feet of physical distance in public spaces, etc.).

The primary purpose of such efforts was not to eradicate COVID-19, but rather to slow the spread of the virus enough to "flatten the curve" and ensure that the medical system, especially intensive care units, were not overburdened while more long-term solutions such as a vaccine were pursued. While governments could act on some of these policies unilaterally (i.e., restricting international travel), many of the health measures required behavioral changes among ordinary individuals. As the White House's coronavirus coordinator explained during the first wave: "There's no magic vaccine or therapy. It's just behaviors: Each of our behaviors translating into something that changes the course of this viral pandemic" (Holland and Mason, 2020). 
We know, however, that not everyone follows public health guidelines, and the current pandemic is no different (Bavel et al., 2020; Roma et al., 2020). A central question for this article, therefore, is to consider who complies? While previous work has explored standard sociodemographic factors like age, sex, education, and political factors like ideology and partisanship (Chen and Farhart, 2020; Merkley et al., 2020; Pickup et al., 2020), COVID compliance is likely rooted in individual differences in personality (see, for example, Nowak et al., 2020). The question for us is which traits and personality profiles result in greater compliance with public health guidelines for social distancing and support for government lockdown policies? To answer this question, we draw on an original dataset of more than 1,700 Canadians. The data contain a series of questions related to COVID compliance and support for the government lockdown, as well as large batteries of both general and dark personality traits.

Given the length of the pandemic, and the onset of multiple waves, encouraging continued (and even increasing) compliance and support for public policies that are aimed at slowing the spread of the virus are crucial. This, however, raises the second question addressed in this article. If compliance is rooted in relatively stable, long-term, factors like personality, how much change can we expect from individuals with regards to their level of compliance? Can greater compliance be encouraged through public health messaging? Moreover, will different traits interact differently with the same public health messages (i.e., will some be more receptive than others)? To explore this second question, we report the results of an original survey experiment where we consider whether providing participants with more information about the upcoming second wave through a series of randomly assigned vignettes would encourage greater self-reported compliance.

Overall, our results reveal that personality is a consistent predictor of both social distancing compliance and support for government lockdown policies. Personality matters even after controlling for a wide range of factors such as age, sex, income, education, employment status, efficacy, knowledge, interest, and partisanship, and while considering the potential mediating role of political ideology. As for the second-wave compliance experiment, we find that public health messaging may have unintended consequences. While those scoring higher in emotionality report greater compliance after being exposed to additional information about the second wave, individuals with higher levels of antagonism (Machiavellianism) report less compliance. As we suggest in the discussion, the fact that public health messaging may not necessarily have a universally positive effect on behavior is a serious challenge for governments seeking to contain the pandemic.

\section{Part 1: Personality and COVID-19 Compliance}

Dozens of published studies have tried to explain why some people comply with measures intended to slow the spread of COVID-19 while others flout these rules and recommendations. Outcome variables have ranged from single item measures of general compliance to identifying specific behaviors such as hand-washing, mask wearing, and maintaining social distance. When examining different correlates, one of the more consistent findings has been political ideology; people on the right of the political spectrum tend to be less compliant (Farias and Pilati, 2020; Painter and Qiu, 2020). Other factors such as trust in science (Plohl and Musil, 2020), trust in government and their ability to implement appropriate policies (Wright et al., 2020; Götz et al., 2021), social capital (Pitas and Ehmer, 2020; Makridis and $\mathrm{Wu}, 2021 ; \mathrm{Wu}, 2021)$, and higher levels of anxiety (Kemp et al., 2021; Mevorach et al., 2021) and fear (Brouard et al., 2020; Harper et al., 2020; Melki, 2020) have helped to explain increased compliance.

While these findings are informative, an important piece of this puzzle likely rests in individual differences in personality. Personality refers to a set of traits that are present in a given individual from an early age, are deeply rooted, and tend to be remarkably stable over time (Costa and McCrae, 1992). Personality consistently predicts a number of personal, political, and health-related outcomes such as job (Judge et al., 2002) and relationship satisfaction (Malouff et al., 2010), voter turnout (Mondak, 2010), political participation (Chen et al., 2020), subjective well-being (Friedman et al., 2010), and overall life expectancy (Bogg and Roberts, 2004). Personality interacts with the environment in influencing specific behaviors; people with different personality traits will focus on different informational cues from their environment (inputs), which will in turn create different options to consider (decision rules), leading to different behavioral choices (outputs; see Larsen et al., 2018). Moreover, the influence of personality on behavior will likely be amplified in situations marked by uncertainty or crisis, such as during a global pandemic. As Caspi and Moffitt (1993): 247 explain:

Personality differences are likely to be revealed during transitions into unpredictable new situations, when there is a press to behave but no information about how to behave adaptively. Dispositional differences are thus accentuated as each person seeks to transform novel, ambiguous, and uncertain circumstances into familiar, clear, and expectable social encounters.

Taken together, there is good reason to expect personality to be related to COVID compliance.

Although the Five Factor Model (FFM; Costa and McCrae, 1992) has long been the predominant model in personality psychology, a separate model, called the HEXACO (Ashton and Lee, 2007), offers a competing nosology. While the traits of extraversion (gregariousness, excitement-seeking), conscientiousness (competence, self-discipline), and openness (ideas, unconventional values) remain largely unchanged, the HEXACO model redefines both agreeableness and neuroticism; agreeableness here is characterized as patience, leniency, and includes lack of anger which in the FFM is noted under neuroticism while neuroticism is renamed emotionality and describes people who are anxious, sentimental, and sensitive (Ashton et al., 2014). The HEXACO model also adds a sixth trait, honesty-humility defined as being honest, sincere, and trustworthy. 
While the FFM and the HEXACO describe general personality traits, the Dark Triad describes the more antagonistic aspects of personality. The Dark Triad, as first described by Paulhus and Williams (2002) includes the three traits of subclinical psychopathy (callousness, impulsivity), narcissism (selfenhancement, antagonism), and Machiavellianism (manipulation, cynicism). While the three traits tend to be significantly correlated and share an antagonistic core, they are three distinct, and multidimensional traits (Miller et al., 2019). In this analysis, we treat them as such.

When examining general personality and COVID-19 compliance, research utilizing the FFM has found that conscientiousness is positively related to general public health compliance (Carvalho et al., 2020; Quian and Yahara, 2020; Götz et al., 2021), while extraversion is negatively related to social distancing (Carvalho et al., 2020; Clark et al., 2020; Götz et al., 2021). There is also evidence that agreeableness (Zajenkowski et al., 2020; Götz et al., 2021) and openness to experience (Clark et al., 2020; Götz et al., 2021) are also related to more compliance. The findings for emotionality are mixed with one study finding that people higher in emotionality are less likely to comply with stay-at-home orders (Clark et al., 2020) while the other finds the opposite result (Götz et al., 2021).

Several studies have also examined the more maladaptive aspects of personality including antisociality, negative affect, detachment, antagonism, and disinhibition. Here, the findings are clear: higher levels of maladaptive traits are related to less compliance with public-health measures (Miguel et al., 2020; Roma et al., 2020; O'Connell et al., 2021). Turning to the specific traits of the Dark Triad, Nowak et al. (2020) find that all three traits are related to engaging in fewer preventative measures. Zajenkowski et al. (2020) similarly find evidence that aspects of all three traits are related to less general compliance.

We add to this emerging literature by using the HEXACO, which to date has been largely omitted, by drawing on fulsome measures of personality, by considering the multidimensional nature of each Dark Triad construct, by utilizing a large representative sample, and by including a variety of theoretically informed control variables in the analysis. In addition to developing our expectations from the results of the existing literature, we further develop these expectations from a theoretical understanding of each personality trait. Three HEXACO traits are particularly relevant for understanding altruistic behavior: honesty-humility (treating others fairly; loyalty), emotionality (preventing harm to oneself and those closely aligned with the individual), and agreeableness (treating others with kindness with no expectation of reciprocity; Ashton and Lee, 2007; Lee and Ashton, 2018). Given that compliance with social measures and support for policies that essentially close public spaces require that individuals sacrifice personal liberties for the greater good, we hypothesize that these traits will be positively associated with compliance and with support for specific policies meant to slow the spread of the coronavirus. To help illustrate how these traits may result in different behaviors, imagine the person higher in honesty-humility. Because of their beliefs in equity, this person might show more negative reactions to media stories of people suffering during the pandemic (input), which would result in more negative appraisals of social interactions that could potentially lead to more infections (decision rules), resulting in the decision to avoid unnecessary gatherings (outputs).

The other three personality traits of the HEXACO model, extraversion, conscientiousness, and openness, represent an individual's level of engagement in "social endeavors, taskrelated endeavors, and idea-related endeavors, respectively" (Ashton and Lee, 2007, p. 160). Given that individuals higher in extraversion would seek out social situations and opportunities to be in the presence of others, we hypothesize that this trait will be negatively related to social distancing compliance and negatively related to support for policies that essentially closed public meeting places. In this way, we expect that extraversion, a trait that is usually associated with positive outcomes (e.g., happiness, leadership success), can be detrimental in certain situations. In contrast, given that conscientiousness is related to dutifulness, rule following, and higher self-control, we expect this trait to be positively associated with all forms of compliance and support for lockdown policies. Openness, characterized by creativity and unconventionality, is consistently related to a less conservative ideology (Osborne and Sibley, 2012; Osborne et al., 2020) and given that conservative ideology has been the most consistent predictor of lower compliance during the pandemic (Gollwitzer et al., 2020; Painter and Qiu, 2020), openness will likely be associated with increased compliance and support for lockdown policies.

Turning now to the Dark Triad, psychopathy is most-often characterized by four underlying facets: interpersonal manipulation (dishonesty), affective (lack of empathy), lifestyle (impulsivity), and antisocial (rule breaking; Williams et al., 2007). People with psychopathic traits place their own needs above others, don't consider the consequences of their actions, and flout rules and regulations. We generally expect to find negative relationships between psychopathy and compliance with social distancing and support for policies. Similarly, both aspects of narcissism, grandiosity (high selfesteem, assertiveness) and vulnerability (envy, shame) are related to self-aggrandizing behavior and placing one's own interests above the interests of others (Crowe et al., 2018; Rosenthal et al., 2020). Both types of narcissism should therefore be negatively related to compliance and support for the lockdown.

While narcissism and psychopathy can be seen as generally maladaptive, the construct of Machiavellianism combines both maladaptive (being selfish and callous) and adaptive features (careful planning, goal-directed). Machiavellians are cunning planners, motivated to achieve their desired ends at any cost (Collison et al., 2018). We therefore expect the antagonistic traits to be related to less compliance and support for policies, while the more adaptive traits of planfulness and deliberation should be positively associated with these outcomes. A summary of our hypotheses is presented in Table $\mathbf{1}$. 
TABLE 1 | Summary of the expectations for each personality construct and social compliance and support for policies to slow the spread of the coronavirus (COVID-19).

\begin{tabular}{lcc} 
& Social compliance & Support for policies \\
\hline Honesty-humility (H) & + & + \\
Emotionality (E) & + & + \\
Extraversion (X) & - & - \\
Agreeableness (A) & + & + \\
Conscientiousness (C) & + & + \\
Openness (O) & + & + \\
SRP: Facet 1 (IPM) & $\mathrm{ns}$ & $\mathrm{ns}$ \\
SRP: Facet 2 (AF) & - & - \\
SRP: Facet 3 (LS) & - & - \\
SRP: Facet 4 (AN) & - & - \\
NVS & - & - \\
NGS & - & - \\
FFMl: Antagonism & - & - \\
FFMl: Agency & $\mathrm{ns}$ & + \\
FFMl: Planfulness & + & $\mathrm{ns}$ \\
\hline
\end{tabular}

Note. + = positive relationship; - = negative relationship; $n s=$ not significant; $S R P=$ SelfReport Psychopathy Scale short form; IPM = interpersonal manipulation; $A F=$ affective; $L S=$ lifestyle; $A N=$ antisocial; FFMI = Five Factor Machiavellianism scale; NVS = Narcissistic Vulnerability Scale; NGS = Narcissistic Grandiosity Scale.

\section{METHODS}

\section{Participants}

Participants were 1725 Canadian residents recruited through a series of voluntary survey panels maintained by Qualtrics. ${ }^{1}$ Participants were sent an email invitation from Qualtrics that contained a link to our survey. Once accessed, the 25-min survey included the following sections: socio-demographics; political attitudes, behaviors, and ambition; COVID-19 attitudes and behaviors; internet usage and activities; and full measures of the HEXACO, Machiavellianism, grandiose and vulnerable narcissism, and psychopathy. Note that the personality batteries were randomly presented to participants. In order to ensure that the sample resembled the broader Canadian population, quotas were put in place for age, income, and sex. The final sample included 863 women, 854 men, and eight nonbinary individuals with an average age of 49 years $(S D=16.6$; range 19-80). The majority of participants identified as White (75.5\%), followed by Asian (13.1\%), Black (2.7\%), other (2.2\%), East Indian (2.0\%), Indigenous (1.7\%), Hispanic (1.3\%), and Middle Eastern (1.3\%). Thirty-one percent of participants had completed a Bachelor's degree followed by equal numbers that reported completing high school (27.2\%), and completing technical or community college $(27.3 \%)$. Median household income ranged between $\$ 50,000$ and $\$ 74,999$. The mean level placement on the one-dimensional measure of political ideology (0-Left to 10-Right) was $4.8(S D=2.2)$. Data were collected between June 29, 2020 and July 22, 2020.

\footnotetext{
${ }^{1}$ The survey included two attention check questions to ensure participants were attentive. Participants who failed the attention checks, along with speedsters and straight liners, were removed from the data.
}

\section{Measures}

\section{Demographics and Controls}

Participants were asked a series of demographic questions. This included their age, sex, income, education, and employment status. Participants were also asked a number of questions about their political attitudes and orientations. This included internal and external efficacy, political knowledge (scored out of five), party identification, political interest, and self-placement on the left/right ideology scale. Combined, these serve as controls in our multivariate analyses. Precise wording of each question is available in the Supplementary Materials.

\section{Personality}

Participants completed the HEXACO-60 (Ashton and Lee, 2009), a 60-item self-report scale that assesses the six personality dimensions of the HEXACO model (10 items per dimension) which includes honesty-humility, emotionality, extraversion, agreeableness, conscientiousness, and openness. Cronbach's alpha coefficients ranged from 0.73 (honesty-humility) to 0.80 (extraversion) in the current sample.

Based on criticisms that truncated measures of the Dark Triad are unable to capture the multidimensionality of each construct (e.g., Miller et al., 2019) and that they may conflate Machiavellianism and psychopathy (Miller et al., 2017; Collison et al., 2018), we used individual measures of each Dark Triad trait. Machiavellianism was measured with the Five Factor Machiavellianism Inventory (FFMI; Collison et al., 2018), a 52-item self-report measure developed from the Five Factor Model of personality. The FFMI contains three subscales: antagonism (e.g., selfishness, callousness), agency (e.g., achievement, competence), and planfulness (e.g., deliberation, order). In the current sample, Cronbach's alpha coefficients were acceptable for all three subscales (range: 0.74 to 0.87 ).

Two aspects of narcissism were measured using the Narcissistic Grandiosity Scale (NGS; Rosenthal et al., 2020) and the Narcissistic Vulnerability Scale (NVS; Crowe et al., 2018). In both of these scales, participants are asked to rate the extent to which a number of adjectives describes how they feel in general and on average (1-not at all to 7-extremely). Items tapping into grandiose narcissism include authoritative, dominant, and superior while items tapping into vulnerable narcissism include envious, resentful, and self-absorbed. Both the NGS and NVS showed acceptable Cronbach's alpha coefficients in the current study (0.92 and 0.90, respectively).

Psychopathy was measured using the Self-Report Psychopathy scale short form (SRP 4 SF; Paulhus et al., 2016) which contains 29 items tapping into the four underlying facets of psychopathy: interpersonal (e.g., manipulation), affective (e.g., callousness), lifestyle (e.g., irresponsible), and antisocial (e.g., delinquent and criminal behavior). The Cronbach's alpha coefficients were acceptable for all four facets in the current study (range: 0.77 to 0.82 ). All personality measures were standardized to a 0 to 100 scale, with 0 representing the lowest level of each personality trait and 100 representing the highest. All possible correlations between the personality scales can be found in the online supplemental materials (Supplementary Table S1). 
TABLE 2 | Correlations between personality variables and outcomes.

\begin{tabular}{|c|c|c|c|c|c|c|c|c|c|c|c|}
\hline & $\mathbf{F 1}$ & F2 & F3 & F4 & NV & NG & M1 & M2 & M3 & DV1 & DV2 \\
\hline $\mathrm{H}$ & $-0.52^{\star \star}$ & $-0.47^{\star \star}$ & $-0.44^{\star *}$ & $-0.39^{* *}$ & $-0.34^{\star *}$ & $-0.41^{\star \star}$ & $-0.63^{\star \star}$ & 0.01 & $0.28^{\star *}$ & $0.24^{* *}$ & $0.17^{\star \star}$ \\
\hline$E$ & $-0.11^{* *}$ & $-0.20^{* *}$ & $-0.11^{\star \star}$ & $-0.11^{\star *}$ & $0.26^{\star *}$ & $-0.16^{\star *}$ & $-0.19^{* *}$ & $-0.38^{\star *}$ & 0.02 & 0.04 & $0.12^{* \star}$ \\
\hline$x$ & $-0.15^{\star \star}$ & $-0.20^{\star *}$ & $-0.09^{\star *}$ & $-0.08^{\star \star}$ & $-0.47^{\star \star}$ & $0.28^{\star \star}$ & $-0.22^{\star *}$ & $0.74^{\star \star}$ & $0.15^{\star \star}$ & 0.01 & $0.08^{\star \star}$ \\
\hline$A$ & $-0.34^{\star \star}$ & $-0.39^{* *}$ & $-0.34^{* \star}$ & $-0.17^{\star \star}$ & $-0.36^{\star *}$ & $-0.18^{* *}$ & $-0.51^{\star \star}$ & $0.18^{\star \star}$ & $0.18^{\star \star}$ & $0.06^{\star *}$ & $0.11^{\star \star}$ \\
\hline C & $-0.29^{\star *}$ & $-0.31^{\star \star}$ & $-0.33^{\star *}$ & $-0.34^{\star \star}$ & $-0.32^{\star \star}$ & -0.02 & $-0.32^{\star \star}$ & $0.46^{\star \star}$ & $0.71^{\star \star}$ & $0.19^{* \star}$ & $0.18^{\star \star}$ \\
\hline $\mathrm{O}$ & $-0.06^{*}$ & $-0.10^{* *}$ & 0.03 & $-0.08^{* *}$ & -0.04 & $0.05^{\star}$ & $-0.16^{\star *}$ & $0.22^{\star *}$ & $0.12^{\star \star}$ & $0.08^{* t}$ & $0.08^{* \star}$ \\
\hline DV1 & $-0.18^{* \star}$ & $-0.21^{* \star}$ & $-0.24^{* \star}$ & $-0.25^{* \star}$ & $-0.13^{* *}$ & $-0.18^{* *}$ & $-0.20^{* *}$ & 0.03 & $0.16^{\star *}$ & - & - \\
\hline DV2 & $-0.19^{* \star}$ & $-0.22^{* *}$ & $-0.16^{\star \star}$ & $-0.21^{\star \star}$ & $-0.06^{\star *}$ & $-0.09^{* *}$ & $-0.23^{* *}$ & 0.05 & $0.18^{* *}$ & $0.28^{* *}$ & - \\
\hline
\end{tabular}

Notes. $H$ = honesty-humility; $E=$ emotionality; $X=$ extraversion; $A=$ agreeableness; $C=$ conscientiousness; $O=$ openness; $D V 1=$ social compliance $(0-100) ; D V 2=$ support COVID-19 policies (O-100); Fl = Self-Report Psychopathy Scale short form (SRP four SF; Paulhus et al., 2015) interpersonal manipulation facet; F2 = SRP affective facet; F3 = SRP lifestyle facet; F4 = SRP antisocial facet; NV = Narcissistic Vulnerability Scale (NVS; Crowe et al., 2018); NGS = Narcissistic Grandiosity Scale (NGS; Rosenthal et al., 2020; M1 = Five Factor Machiavellian Inventory (FFMI; Collison et al., 2018) antagonism facet; $M 2$ = FFMl agency facet; $M 3$ = FFMI planfulness facet.

${ }^{*} p<.05$.

${ }^{* *} p<.01$ (2-tailed)

\section{Outcomes}

Participants were asked to think back to when the COVID-19 lockdown was in full effect and to indicate the extent to which they engaged in the following behaviors (0-never to 100frequently): visit someone's else's home, have guests in their home, and gather outdoors with people who did not live with them. Items were reversed scored so that higher scores indicated more compliance with social distancing measures. We conducted a principal components analysis (PCA) with varimax rotation to assess whether the three social compliance items could be combined into one measure. A one-factor solution accounting for $79.46 \%$ of the variance was found (eigenvalue $=2.38$; Cronbach's alpha $=0.87$ ). The average rating across the three items was therefore taken as the measure of social distancing compliance, with higher scores indicating more compliance with social distancing measures.

Participants were then asked the extent to which they supported the following governmental initiatives during the lockdown (0-not at all supportive to 100-completely supportive): closing daycares, schools, and universities; closing bars and restaurants; closing parks and playgrounds; forbidding public gatherings where many people are gathered at one place (i.e., sporting, religious, and cultural events); and forbidding nonnecessary travel. A PCA confirmed a one-factor solution accounting for $80.53 \%$ of the variance (eigenvalue $=4.03$; Cronbach's alpha $=0.94)$ and the average of the five items was calculated as the measure of support for policies with higher scores indicating more support for these policies. Tables of the rotated factor loadings for each composite variable can be found in the online supplemental materials (Supplementary Tables S2, 3).

\section{Part 1: Observational Results}

We begin by exploring compliance with public health guidelines regarding social distancing. ${ }^{2}$ Table 2 presents the zero-order

${ }^{2} \mathrm{~A}$ table of descriptive information for every control variable, personality inventory, and outcome variable is available in the Supplementary Materials (Table 4S). correlations between the personality constructs and the two outcomes: social distancing compliance and support for lockdown policies. The bivariate associations are almost entirely consistent with the expectations outlined in Table 1, with the exception of extraversion which was not significantly related to social compliance and showed a small positive relationship with support for lockdown policies.

To explore these relationships further, we estimated a series of Structural Equation Models (SEM). In these models, we include the various personality traits (or facets) as observed (independent) variables, along with a robust set of controls for respondent age, sex, income, education, employment status, political efficacy (internal and external), political knowledge, political interest, and party identification. While we are primarily interested in the direct effects of personality on COVID behaviors and lockdown policy attitudes, we suspect that personality may, in fact, be mediated through other relevant factors. Given the well documented link between personality and ideological orientation (Mondak, 2010; Osborne and Sibley, 2012; Sibley et al., 2012; Osborne et al., 2020) as well as the importance of ideology for understanding COVID related outcomes (Brouard et al., 2020; Farias and Pilati, 2020; Merkley et al., 2020; Painter and Qiu, 2020), and political attitudes and behaviour more generally (Inglehart, 1997; van der Meer et al., 2009; Feldman and Johnston, 2014), our SEM models include left-right ideology as a possible mediator. We estimate these models using maximum likelihood estimation with bootstrapped standard errors. Path diagrams show significant paths with solid lines and their associated coefficients whereas insignificant paths are shown with dotted lines.

Much of the Dark Triad literature has been criticized for failing to take into account the "perils of partialing" when multivariate models are used. Here, the argument is that the residual traits produced when all Dark Triad traits are included in the same model cannot be readily interpreted because they may not resemble the original traits (Sleep et al., 2017). As Miller et al. (2019:355) note, this concern is exacerbated "when variables are substantially correlated and multidimensional as they are for the dark triad". Given that we are considering this multidimensionality and that the traits are in fact significantly 


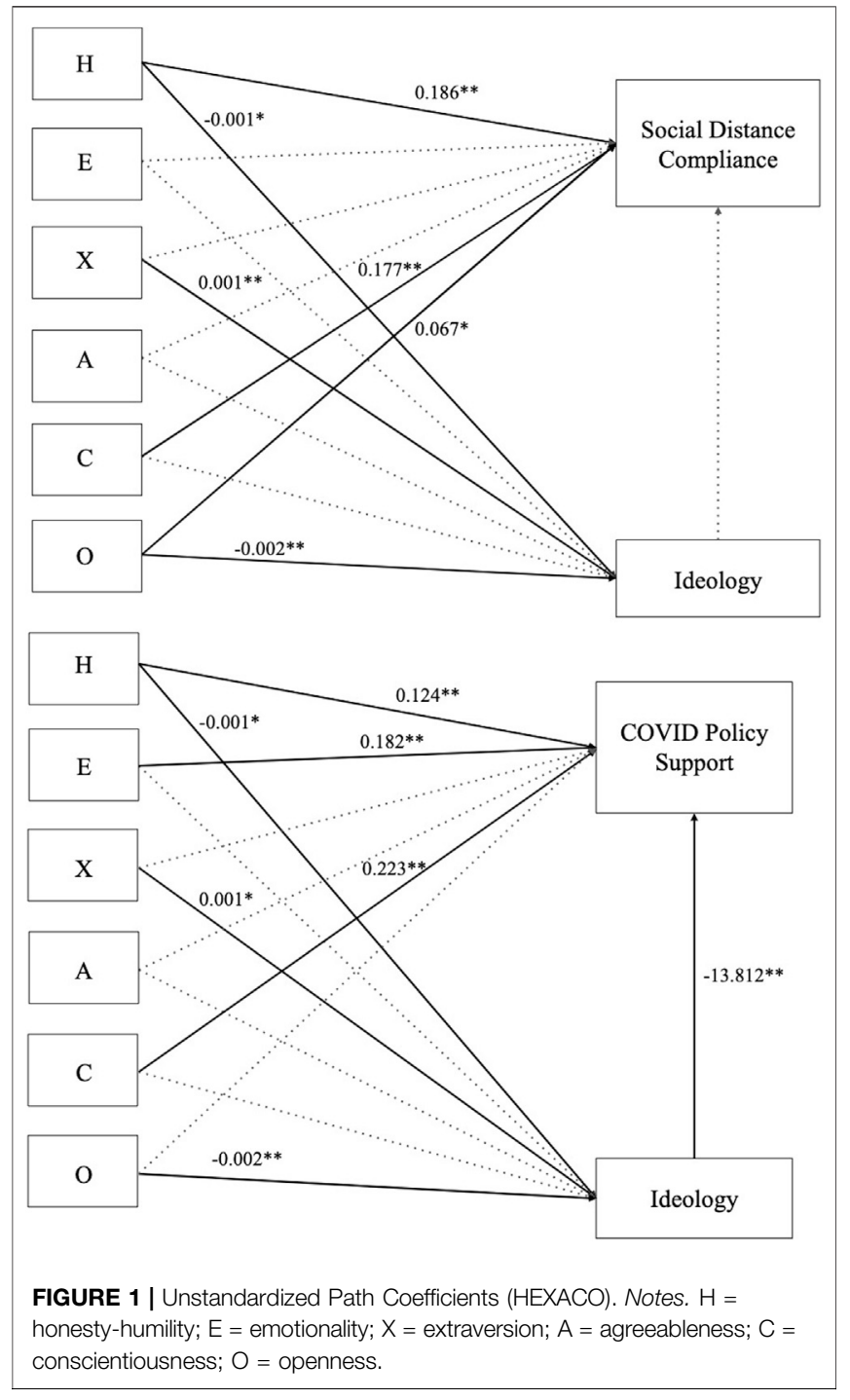

correlated (supplementary Material Table S1), we specify a number of separate models, one for each of the personality models under investigation (HEXACO, narcissism, psychopathy, and Machiavellianism). In total, then, we conducted eight SEM models (four for each outcome). All were deemed to fit the data well according to recommendations from Byrne (1994). The Root Mean Square Error of Approximation (RMSEA) for all models was $<0.001$, well under the cut-off of 0.08. The Standardized Root Mean Square Residual (SRMR) was also $<0.001$ for all models easily under the cut-off of 0.10 . The $\chi^{2}$ for the models ranged from 675.1 [33] to 815.0 [41] and all achieved $p$-values $<0.001$. The comparative fit indices for all eight models were in excess of 0.99 . Taken together, the models employed fit the data well.

Figure 1 includes the SEM path diagram results regarding the relationship between the HEXACO and our two COVID outcomes. On the top panel, we see that three general personality traits, honesty-humility, conscientiousness, and openness, are positively related to social distancing compliance. We also find that extraversion is negatively related to self-reported social distancing, however this is only the case at the $p<0.100$ level. Interestingly, no indirect effects of personality through ideology on social distancing were identified. On the bottom panel are the paths for lockdown support. Here we see that those scoring higher on honesty-humility, emotionality, and conscientiousness tend to be more supportive of government lockdown policies. Although not shown in the path diagram, two traits also have indirect effects on lockdown support through ideology: extraversion $(-0.014 ; p=0.018)$ and openness $(0.031$; $p=0.000)$.

Figures 2-4 contain the path diagrams for the dark traits of Machiavellianism, psychopathy, and narcissism. As was the case for the HEXACO model, we find only direct effects of personality on social distancing compliance, and both direct and indirect effects (mediated through ideology) for lockdown policy support. Beginning with Figure 2, we see that two facets of Machiavellianism are related to compliance with social distancing. As expected, the antagonism facet is negatively related to compliance whereas the planfulness facet is

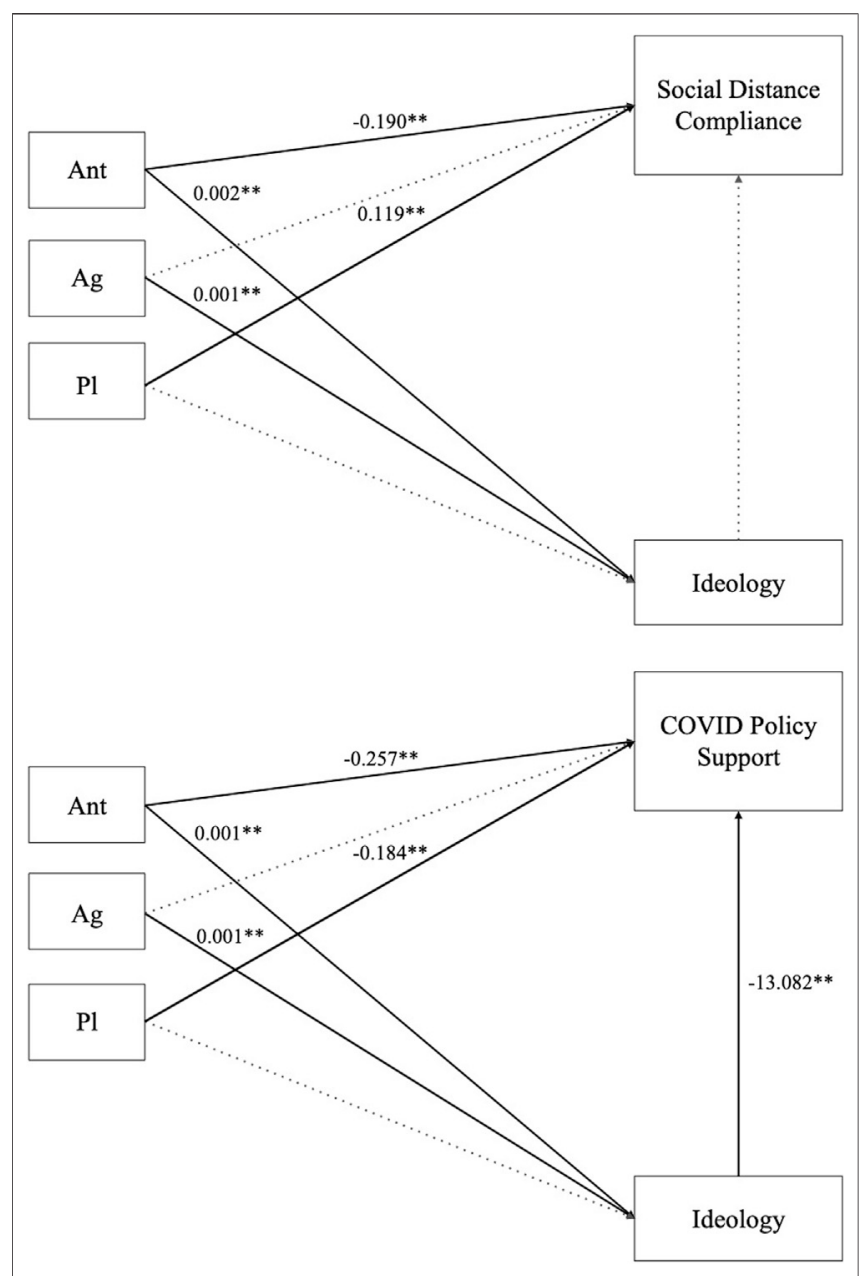

FIGURE 2 Unstandardized Path Coefficients (Machiavellianism). Notes. Ant = antagonism; $\mathrm{Ag}=$ agency; $\mathrm{Pl}=$ planfulness . 


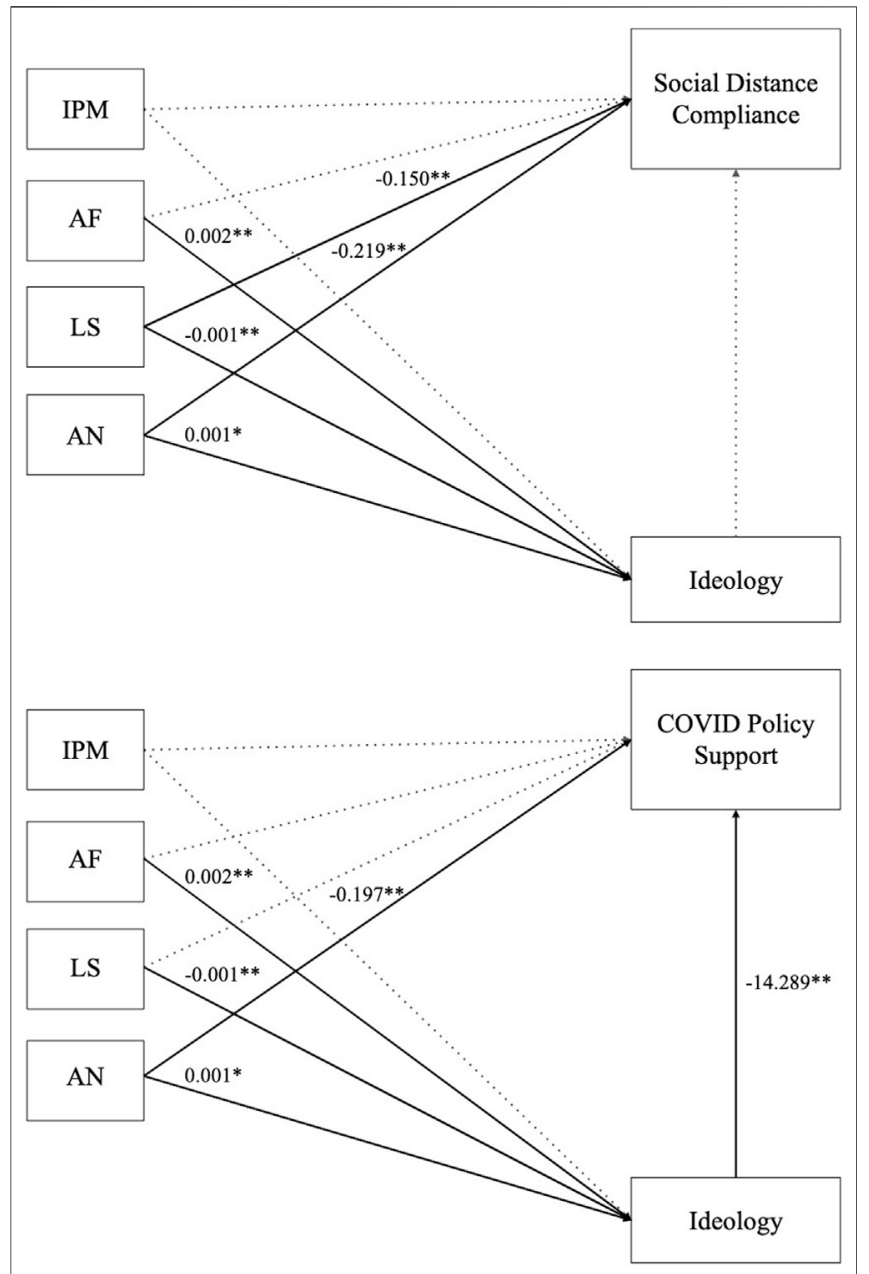

FIGURE 3 | Unstandardized Path Coefficients (Psychopathy). Notes.

$\mathrm{IPM}=$ interpersonal manipulation; $\mathrm{AF}=$ affective; $\mathrm{LS}$ = lifestyle; $\mathrm{AN}=$ antisocial.

positively related to compliance. The same pattern is identified with regards to direct effects of lockdown support. Here we also find indirect effects of two Machiavellianism facets through ideology on lockdown support: antagonism $(-0.019 ; p=0.014)$ and agency $(-0.019 ; p=0.013)$.

Figure 3 reports the results for psychopathy. We find partial support for our expectations regarding this trait in so far as the behavioral and antisocial aspects of psychopathy are in fact related to less compliance (see antisocial and lifestyle paths). Surprisingly, however, the affective facet, characterized by callousness and lack of empathy was insignificant. When considering lockdown support, only those scoring higher on the antisocial facet are significantly less supportive of lockdown policies. Three facets, affective $(-0.027 ; p=0.007)$, lifestyle $(0.020 ; p=0.018)$, and antisocial $(-0.016 ; p=0.030)$, also have indirect effects on lockdown support which are mediated through ideology.

Finally, Figure 4 contains the SEM results for grandiose and vulnerable narcissism. Considering social distancing, those higher in grandiose narcissism report significantly less compliance. The path for vulnerable narcissism, by contrast, is insignificant. We find a similar pattern for lockdown support: only grandiose narcissism is significantly related to less support for the lockdown. Grandiose narcissism also has a significant indirect path $(-0.019 ; p=0.003)$ through political ideology.

When it comes to personality and COVID behaviors, specifically social distancing, we observe direct and unmediated effects only. When examining support for lockdown policies, however, we observe not only direct effects of personality, but also a number of indirect effects mediated through ideology. In terms of who complies, the results of these analyses provide compelling evidence that prosocial traits (honesty-humility, conscientiousness, and openness), are related to more social distancing compliance whereas antisocial traits (Machiavellianism, psychopathy, and narcissism) are related to less compliance.

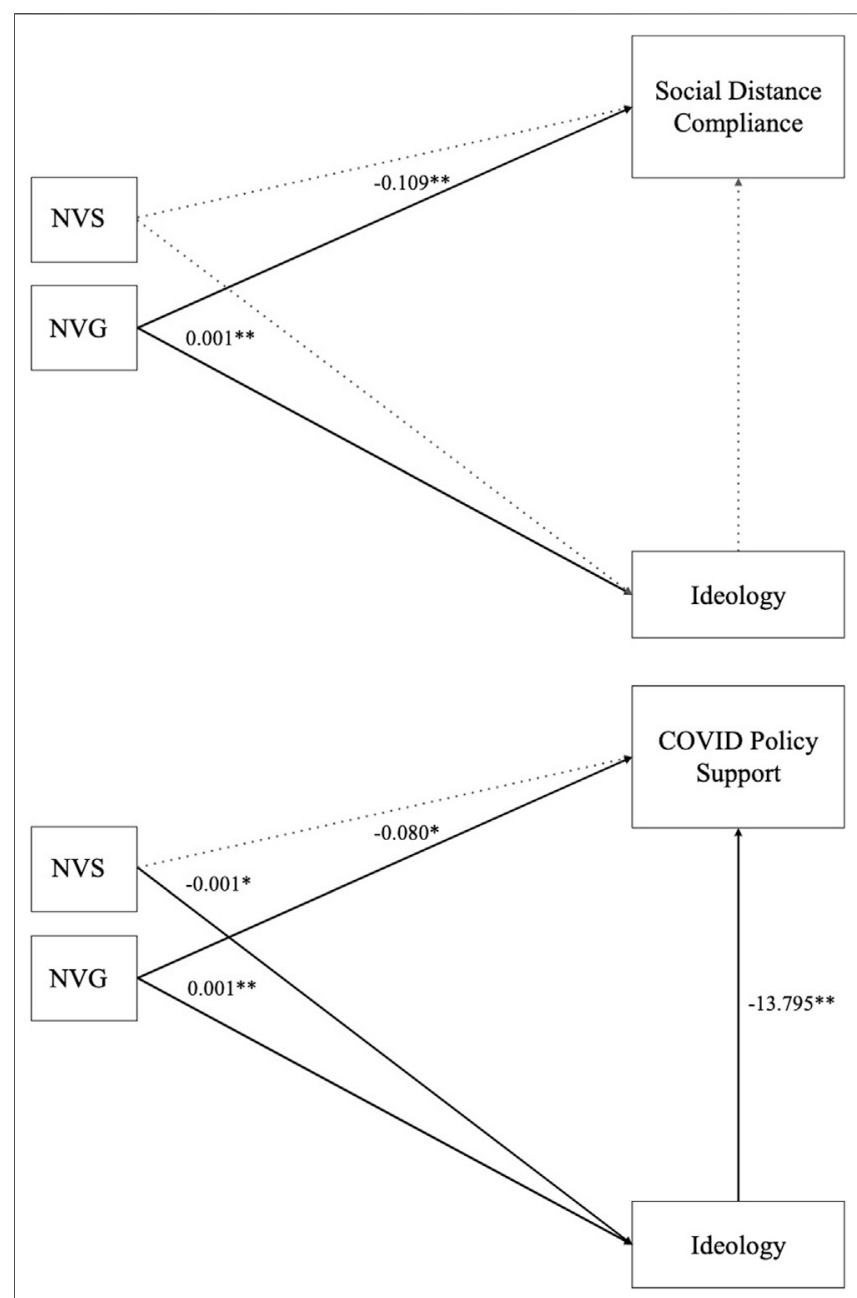

FIGURE 4 | Unstandardized Path Coefficients (Narcissism). Notes. NVS = vulnerable narcissism; NGS = grandiose narcissism. 


\section{Part 2: Personality and Public Health Messaging}

As the first part of our empirical analysis demonstrates, personality traits are important correlates of compliance with COVID-19 preventative measures and support for various COVID-19 lockdown policies. Public health compliance, however, does not occur in a vacuum. One vital component of the response to the current pandemic is public-facing messaging from a variety of sources including the government, public health officials, and the media (Ataguba and Ataguba, 2020; Banerjee and Rao, 2020; Sevi et al., 2020). There is also good reason to expect that personality traits will alter an individual's receptiveness to this political/public health messaging (Mondak, 2010; Chen, 2015). The second part of our analysis, therefore, embeds a survey experiment with varying levels of information to better understand how different personality traits affect an individual's receptiveness to public health messaging.

\section{Literature and Expectations}

Individuals are exposed to persuasive appeals on a daily basis. Whether it is governments trying to change citizen behavior, businesses trying to sell goods and services, or political actors seeking support in the form of votes and donations, persuasive appeals are everywhere (Matz et al., 2017). While only just emerging, there are already several pieces of research that explore the types of appeals and messages (i.e., norm based, moral, etc.) that could be used to encourage greater COVID-19 compliance (Bilancini et al., 2020; Everett et al., 2020; Jordan et al., 2020; Utych and Fowler, 2020). While there is not yet a consensus regarding the most effective communication strategies for COVID-19, there is a clear consensus that messaging matters. As Bilancini et al. (forthcoming) write, "the importance of finding efficient messages is clear, as they represent an easy and potentially scalable intervention: messages can be texted by phone, spread on social media, put inside postal boxes, and even voiced in the streets using cars equipped with a megaphone."

Given that persuasive communication is routine, it is not surprising that there is a large literature regarding the effectiveness of such appeals (Moon, 2002; Hirsh et al., 2012; Dubois et al., 2016). On the political science side, scholars have largely accepted the role of political communication in shaping opinion and behavior, though this is often understood through subtle effects such as framing, priming, and agenda setting (Iyengar, 1990; Miller and Krosnick, 1997). Content and source cues have also been identified as important considerations when understanding the influence of political communication, such that partisanship and credibility are often intertwined in the public's minds as they consider communication (Goren et al., 2009; Laustsen and Petersen, 2016). Reviewing the more psychological literature, research has found that tailoring messages to specific traits of the intended target appears to amplify the effect of the message (Hirsh et al., 2012; Matz et al., 2017). In this sense, different appeals are better suited for individuals with different traits.

Despite academic research on the effectiveness of tailoring, much of the work in public health communication focuses on the value of generalized public health communication without understanding how individual or situational differences influence receptiveness to these messages (Bernhardt, 2004; Freimuth and Quinn, 2004). This isn't entirely surprising. After all, Freimuth and Quinn (2004:2054) note that "health communicators often struggle to understand the audiences they seek to reach." In the Canadian case, a common theme in COVID-19 messaging has been a focus on the trajectory and spread of the disease with a near constant reporting of both current and projected rates of infections and deaths in Canada (Agius et al., 2020; Government of Canada, 2021) as well as on the global scale (CBC, 2021; Dunham, 2021). In focusing on this content, the strategy has been to broadcast information to the entire population (using government websites, press briefings, etc.) as opposed to engaging in more tailored messaging or narrowcasting. ${ }^{3}$ Under this approach, recipient characteristics are largely taken as static or constant. While such an approach may have been effective historically, as science and public health have become more politicized, broadcasting a single message may no longer produce the desired outcome (Motta et al., 2018, 2020). We should expect personality to make some individuals more receptive to public health messaging than others. In fact, a message that increases compliance for one recipient may, in fact, decrease compliance for another (Feng and MacGeorge, 2006). Political scientists and psychologists have long understood the conditional nature of the relationship between personality and behavior (Lavine and Snyder, 1996).

Overall, we are left with the following: messages tend to be more effective when tailored to psychological factors like personality; public health messages regarding the pandemic in Canada have been largely static (untailored) and applied to the population as a whole through broadcasting; and in the absence of tailored messages, there is evidence to suggest that recipient traits will alter receptiveness to that messaging. It is this latter issue that we are particularly interested in and seek to address here. The question is whether general public health reporting that focus on the trajectory of the pandemic (as currently employed by the government and media) will have a universal effect or whether there will be differences in receptivity based on specific personality traits. While it remains plausible to design messaging for specific personality traits, we focus on the predominant messaging strategy (universal messages based on the pandemic trajectory) and investigate whether these messages are more or less persuasive for some members of the population, conditional on their personality traits.

Given the limited research examining the HEXACO and Dark Triad as they relate to receptiveness to political appeals in general and health messaging in particular, we approach this as an exploratory analysis. Our expectation is that certain traits will make individuals more or less receptive to general messages that are framed around the scale of the pandemic (infections, deaths,

\footnotetext{
${ }^{3}$ This broadcasting approach to the pandemic has been criticized. Hodson (2020), for instance, writes that the Canadian "government and public health communicators are generally using old control-the-message tactics to reach people, and this is a losing proposition."
} 
etc.) but that a universal, unidirectional, effect is unlikely. Take, for example, individuals scoring higher in the trait of emotionality. These individuals are characterized as having heightened fear of physical danger and elevated levels of anxiety and stress. These individuals are also empathetic, caring, and prosocial. Given their personality profile, those higher in emotionality may be particularly susceptible to messages that provide examples of the number of infections and deaths, leading to greater public health compliance. At the same time, individuals who are callous, unempathetic, and selfinterested may react quite differently.

\section{METHODS}

The experimental analysis reported here utilizes the same dataset as described above but examines the conditional effects of a variety of public health messages on an individual's likelihood of engaging in protective health behaviors. Thus, most procedures are identical to what has already been detailed. Below, however, we document the instances where methodological procedures differ. In particular we provide details on the experimental manipulation and our dependent variable.

\section{Manipulation and Outcome}

In addition to their current level of compliance (observational results discussed above), participants were also asked to think about their future behavior and how they would act should a second wave of the pandemic occur. Before answering this second set of questions, however, participants were randomly assigned to one of three information conditions where we manipulated the specificity of the projected number of additional infections and deaths that could occur during the second wave. ${ }^{4}$ Two experimental conditions, one focusing on Canada and the other on the World Health Organization, were adopted to reflect actual reporting practices at the time, which frequently included the scale of the pandemic in Canada and abroad (Agius et al., 2020; CBC, 2021; Dunham, 2021; Government of Canada, 2021). While the source of the information changes between the two experimental conditions (Canada vs. World Health Organization) to match the scale of the severity of the numbers being reported, recent polling data suggests that Canadians are satisfied with the COVID response by their national government as well as the World Health Organization (Mordecai, 2020). The change in the source of the information was, therefore, not expected to influence the results but to maximize external validity.

All three conditions began with the same preamble: "Health officials widely expect the coronavirus pandemic to follow a

${ }^{4}$ Balance tests show that age, sex, income, education, nor ideology predict condition assignment. Nonetheless, out of an abundance of caution, we include these as controls in our analyses. Results are substantively similar when the control variables are excluded. similar pattern to previous pandemics, with a "second wave" of infections occurring in the fall. This wave is expected to be similar in size or larger than the first wave of infections." In the first condition, no further information was provided. Participants in the second condition read one additional statement that provided some Canadian-specific projections of infections and deaths for the second wave from the "Public Health Agency of Canada" (e.g., 30,000 to 40,000 additional infections) while participants in the third condition were provided with worldwide projections from the "World Health Organization" (e.g., six to seven million additional infections).

Following the vignettes, participants were asked to indicate the likelihood that they would engage in the following behaviors (0-never to 100-frequently): visit someone's else's home, have guests in their home, and gather outdoors with people who did not live with them. Items were reversed scored so that higher scores indicated more compliance with social distancing measures and, similar to part 1, scores were averaged across all three items to produce one score indicating compliance (Supplementary Material Table S5 contains the rotated factor loadings from the PCA). We utilize these responses as a post-treatment measure of public health compliance. To generate our outcome variable, we subtract the aggregated pre-treatment responses to the public health behavior questions from the posttreatment responses. Positive numbers, therefore, represent a higher likelihood of engaging in the behaviors relative to their responses pre-treatment and negative numbers represent a lower likelihood of engaging in the behaviors relative to pretreatment responses.

\section{Part 2: Experimental Results}

We begin our analysis by looking at the results pooled across the various information conditions, presented in Table 3. While these results aren't experimental per se, they allow us to see if the mere presence of public health information about a second pandemic wave would increase (or decrease) public health compliance. Since we use a pre-post difference measure, any significant effects here should indicate a change in public health compliance between an individual's stated compliance prior to reading a vignette about a second pandemic wave and their responses after the vignette. Since we pool across conditions, this table simply shows whether personality traits affected receptiveness to any public health messaging about the second wave. In other words, does being confronted with the possibility of a second wave (regardless of its scale) influence compliance?

As the results show, there is a limited effect of general personality on messaging across the pooled conditions: the trait of honesty-humility leads to less projected second-wave compliance. Interestingly, this may reflect a true tendency towards less compliance or it could demonstrate a tendency towards honest survey response answers. If agreeing to engage in social distancing in the face of a second pandemic wave is considered socially desirable, then honesty-humility may predict more honest answers but not necessarily lower 
TABLE 3 | Linear regression analysis of effect of public health messaging (pooled) on public health compliance.

\begin{tabular}{|c|c|c|c|c|c|c|c|c|c|c|}
\hline & \multicolumn{2}{|c|}{ Model $1(N=1690)$} & \multicolumn{2}{|c|}{ Model $2(N=1681)$} & \multicolumn{2}{|c|}{ Model $3(N=1684)$} & \multicolumn{2}{|c|}{ Model $4(N=1684)$} & \multicolumn{2}{|c|}{ Model $5(N=1674)$} \\
\hline & B & SE & B & SE & B & SE & B & SE & B & SE \\
\hline Age & -0.02 & 0.03 & 0.01 & 0.03 & -0.02 & 0.03 & -0.01 & 0.03 & -0.01 & 0.03 \\
\hline Sex (Male) & -0.37 & 0.87 & -0.27 & 0.97 & -0.00 & 0.91 & -0.47 & 0.88 & -0.15 & 0.91 \\
\hline Income & -0.10 & 0.20 & -0.09 & 0.21 & -0.07 & 0.20 & -0.15 & 0.21 & -0.09 & 0.21 \\
\hline Education & -0.08 & 0.42 & -0.22 & 0.43 & -0.04 & 0.42 & -0.19 & 0.42 & 0.01 & 0.42 \\
\hline Ideology & $-0.52^{\star \star}$ & 0.20 & $-0.46^{*}$ & 0.20 & $-0.48^{\star}$ & 0.20 & $-0.51^{\star}$ & 0.20 & $-0.51^{\star}$ & 0.20 \\
\hline $\mathrm{H}$ & & & $-0.08^{\star}$ & 0.03 & & & & & & \\
\hline$E$ & & & 0.03 & 0.03 & & & & & & \\
\hline$x$ & & & -0.04 & 0.03 & & & & & & \\
\hline$A$ & & & 0.06 & 0.03 & & & & & & \\
\hline C & & & 0.03 & 0.04 & & & & & & \\
\hline 0 & & & 0.05 & 0.03 & & & & & & \\
\hline SRP F1 & & & & & $-0.13^{\star *}$ & 0.04 & & & & \\
\hline SRP F2 & & & & & 0.02 & 0.05 & & & & \\
\hline SRP F3 & & & & & 0.02 & 0.04 & & & & \\
\hline SRP F4 & & & & & 0.08 & 0.05 & & & & \\
\hline NVS & & & & & & & -0.01 & 0.02 & & \\
\hline NGS & & & & & & & 0.03 & 0.02 & & \\
\hline FFMl Ant & & & & & & & & & 0.01 & 0.04 \\
\hline FFMl Ag & & & & & & & & & -0.04 & 0.04 \\
\hline FFMI PI & & & & & & & & & 0.04 & 0.03 \\
\hline $\mathrm{R}$ & 0.01 & & 0.01 & & 0.01 & & 0.01 & & 0.01 & \\
\hline
\end{tabular}

Note. $H$ = honesty-humility; $E$ = emotionality; $X$ = extraversion; $A$ = agreeableness; $C$ = conscientiousness; $O=$ openness; SRP F1 = interpersonal manipulation; SRP F2 = affective; SRP F3 = lifestyle; SRP F4 = antisocial; NVS = vulnerable narcissism; NGS = grandiose narcissism; M1 = Machiavellianism antagonism facet; M2 = agency facet; M3 = planfulness facet. ${ }^{*} p<.05$.

${ }^{* *} p<.01$.

${ }^{* * *} p<.001$.

responsiveness to messaging. Turning to the Dark Triad, we again see only a limited effect for personality. We do, however, see that those scoring higher on the interpersonal (manipulation) facet of psychopathy are less responsive to messaging. As a whole, however, these results demonstrate that, pooled across conditions, there is little effect for personality traits in driving responsiveness to public health messages.

Of course, examining pooled results misses the potential for differential effects based on the content of the messaging. Thus, while personality may not play a particularly strong role in responsiveness to messaging writ large, it's possible (and likely) that specific types of messages produce responses that are contingent on personality. To examine this possibility, Table 4 presents the results with interactions between the various personality traits and whether an individual saw the control condition (no specific information) or one of the two treatment conditions where personality appears to play a modest role when accounting for the content of the message. Here we pool the two informational conditions together as there were no significant differences between these conditions. In this sense we are comparing those who received general information about the possibility of a second wave to those who received more specific information about the second wave, including projections of infections and deaths. Exploring differences between the control and treated conditions, we find that there is a significant interaction effect for the treated condition assignment with emotionality. That is, while emotionality does not predict greater public health compliance when individuals are reminded about the potential second wave (Table 3 ), higher levels of emotionality do predict a higher likelihood of complying when the information contains projected deaths and infections. We also see the opposite effect for those scoring higher on the antagonism factor of Machiavellianism. In this case more specific information regarding deaths and infections results in lower compliance. ${ }^{5}$

\section{DISCUSSION AND CONCLUSION}

This article adds to the emerging literature on personality and public health compliance, specifically as it relates to COVID19 social distancing and support for government lockdown policies. Our study benefits from a large representative sample and fulsome batteries of a variety of measures of personality (HEXACO, FFMI, etc.). In fact, we utilize more than 150 unique items to assess the traits studied here. As we expected, the observational results clearly reveal that both general and dark traits are related to public health compliance in predictable ways. When examining compliance with social distance measures, we find honest

${ }^{5}$ We extend our analysis in the supplemental materials. Here we report the results of a number of marginal effects calculations that reach marginal significance $(p<0.10)$. 
TABLE 4 | Linear regression analysis of effect of public health messaging on public health compliance, by control or treatment condition assignment.

\begin{tabular}{|c|c|c|c|c|c|c|c|c|c|c|}
\hline & \multicolumn{2}{|c|}{ Model $1(N=1690)$} & \multicolumn{2}{|c|}{ Model $2(N=1681)$} & \multicolumn{2}{|c|}{ Model $3(N=1684)$} & \multicolumn{2}{|c|}{ Model $4(N=1684)$} & \multicolumn{2}{|c|}{ Model $5(N=1674)$} \\
\hline & B & SE & B & SE & B & SE & B & SE & B & SE \\
\hline Age & -0.02 & 0.03 & 0.01 & 0.03 & -0.01 & 0.03 & -0.01 & 0.03 & -0.01 & 0.03 \\
\hline Sex (Male) & -0.36 & 0.87 & -0.19 & 0.97 & 0.06 & 0.91 & -0.46 & 0.88 & -0.09 & 0.91 \\
\hline Income & -0.10 & 0.20 & -0.07 & 0.21 & -0.06 & 0.20 & -0.16 & 0.21 & -0.07 & 0.21 \\
\hline Education & -0.08 & 0.42 & -0.23 & 0.43 & -0.07 & 0.42 & -0.18 & 0.42 & -0.01 & 0.42 \\
\hline Ideology & $-0.52^{\star \star}$ & 0.20 & $-0.46^{*}$ & 0.20 & $-0.49^{\star}$ & 0.20 & $-0.51^{\star}$ & 0.20 & $-0.53^{* *}$ & 0.20 \\
\hline Pooled treatment & 0.15 & 0.92 & -9.81 & 7.31 & 1.19 & 1.51 & -0.34 & 1.97 & 10.04 & 6.54 \\
\hline $\mathrm{H}$ & & & -0.10 & 0.06 & & & & & & \\
\hline $\mathrm{H} \times$ treated & & & 0.03 & 0.07 & & & & & & \\
\hline E & & & -0.06 & 0.05 & & & & & & \\
\hline$E \times$ treated & & & $0.13^{\star}$ & 0.06 & & & & & & \\
\hline$x$ & & & -0.00 & 0.05 & & & & & & \\
\hline $\mathrm{X}$ treated & & & -0.05 & 0.07 & & & & & & \\
\hline$A$ & & & 0.04 & 0.06 & & & & & & \\
\hline A $x$ treated & & & 0.03 & 0.07 & & & & & & \\
\hline C & & & 0.01 & 0.06 & & & & & & \\
\hline $\mathrm{C} \times$ treated & & & 0.02 & 0.08 & & & & & & \\
\hline $\mathrm{O}$ & & & 0.05 & 0.05 & & & & & & \\
\hline $\mathrm{O} \times$ treated & & & 0.01 & 0.06 & & & & & & \\
\hline SRP F1 & & & & & -0.08 & 0.08 & & & & \\
\hline SRP F1 $x$ Treated & & & & & -0.06 & 0.09 & & & & \\
\hline SRP F2 & & & & & 0.06 & 0.08 & & & & \\
\hline SRP F2 x Treated & & & & & -0.06 & 0.10 & & & & \\
\hline SRP F3 & & & & & -0.03 & 0.07 & & & & \\
\hline SRP F3 x Treated & & & & & 0.09 & 0.08 & & & & \\
\hline SRP F4 & & & & & 0.13 & 0.08 & & & & \\
\hline SRP F4 x Treated & & & & & -0.08 & 0.10 & & & & \\
\hline NVS & & & & & & & -0.03 & 0.04 & & \\
\hline NVS $\times$ treated & & & & & & & 0.03 & 0.05 & & \\
\hline NGS & & & & & & & 0.03 & 0.04 & & \\
\hline NGS $\times$ treated & & & & & & & -0.00 & 0.05 & & \\
\hline FFMl Ant & & & & & & & & & 0.11 & 0.06 \\
\hline FFMl Ant $x$ treated & & & & & & & & & $-0.15^{\star}$ & 0.08 \\
\hline FFMl Ag & & & & & & & & & -0.00 & 0.06 \\
\hline FFMl $\mathrm{Ag} \times$ treated & & & & & & & & & -0.05 & 0.07 \\
\hline FFMI PI & & & & & & & & & 0.06 & 0.05 \\
\hline FFMI PI $x$ treated & & & & & & & & & -0.02 & 0.07 \\
\hline $\mathrm{R}$ & 0.01 & & 0.02 & & 0.01 & & 0.01 & & 0.01 & \\
\hline
\end{tabular}

Note. $H$ = honesty-humility; $E=$ emotionality; $X=$ extraversion; $A$ = agreeableness; $C=$ conscientiousness; $O=$ openness; SRP F1 = interpersonal manipulation; SRP F2 = affective; SRP F3

= lifestyle; SRP F4 = antisocial; NVS = vulnerable narcissism; NGS = grandiose narcissism; M1 = Machiavellianism antagonism facet; $M 2$ = agency facet; $M 3$ = planfulness facet.

${ }^{*} p<.05$.

${ }^{* *} p<.01$.

${ }^{* * *} p<.001$.

rule-followers (honesty-humility), careful and deliberate planners (conscientiousness), and inquisitive and unconventional thinkers (openness) exhibit greater compliance with social distancing. We also see that the entitlement, callousness, and self-interest that characterize the Dark Triad traits also result in lower levels of compliance. Turning to lockdown support, we find that a wider range of personality traits are significant. Here we see that each of the Dark Triad traits are negatively related to support for government lockdown policies while general traits such as emotionality, honesty-humility, and conscientiousness are positively related. Interestingly, emotionality does not exert consistent influence over the two outcomes. Individuals scoring higher in this trait support government lockdown action to slow the spread of the virus even if it doesn't translate into higher levels of compliance for themselves personally.

The experimental results show that even small differences in messaging (like including or excluding specific information about the number of infections and deaths) can alter the effect of some personality traits on compliance. These results, of course, do not demonstrate overwhelming effects of personality conditional on treatment assignment. We venture, however, that this illustrates the potential for public health messaging to exert a differential effect based on the recipient's personality traits. For some individuals, such as those higher on emotionality (fearful, anxious, sentimental, etc.), being confronted with more information about the severity of the second-wave resulted in higher levels of selfreported social distancing compliance. At the same time, 
however, we find evidence that exposure to the same public health messaging reduced compliance among those scoring higher on the antagonism factor of Machiavellianism. Unintended messaging effects around COVID-19 have been reported elsewhere. In a study of age-based messaging strategies, Utych and Fowler (2020: 7) report that providing information on the threats to older individuals has no positive effects on behavior or attitudinal change. In fact, they find that providing this information creates negative effects. As they conclude "when targeting messages towards younger Americans, a focus on threats to older adults could potentially be counterproductive."

The findings reported here have a number of important implications. First, the observational analysis reveals that while much emphasis has been placed on factors like partisanship and ideology, individual differences in personality are also an important part of the puzzle. Second, our experimental analysis reveals some potential unintended messaging effects whereby exposure to public health messaging leads to less social distancing compliance. These unintended effects demonstrate an important challenge faced by politicians and public health professionals in their response to the pandemic. While we may hope that a universally appealing message could be developed to encourage greater compliance among the populace writ large, our results suggest that this may be a difficult task to achieve. ${ }^{6}$ In the absence of a universally appealing message, however, the results of our observational and experimental analysis combine to suggest that communication tailoring may be an avenue worth pursuing. In the age of big data (Kosinski et al., 2013) where psychological targeting already occurs (Hirsh et al., 2012; Matz et al., 2017), public health messages that are targeted to match a recipient's individual personality may be an important tool to encourage compliance and slow the spread of the virus. While the specific messages that may produce these effects is beyond the scope of this manuscript, we encourage this type of work from both academics and public health professionals.

While this study makes a number of important contributions, it is not without limitations. First, this is a cross-sectional study that was conducted during the first wave of the pandemic. Unlike a longitudinal study that collects data at multiple points in time, we cannot actually measure second-wave compliance. Instead, our social distancing measures and planned future compliance rely on self-reporting. Due to social desirability, our selfreport measures may overestimate compliance. While our approach is consistent with the majority of the literature on the subject, it is in contrast to a small number of studies that

${ }^{6} \mathrm{We}$ note, though, that with political and public health messaging, the content of the message may alter the traits that predict compliance. Thus, while we find that certain traits lead to greater or less compliance with our experimental messages that focus on the trajectory of the virus, there likely exist alternative messaging strategies that could produce entirely different patterns of results. have been able to draw upon behavioral measures using cellphone mobility data (see Wright et al., 2020; Jay et al., 2020). Second, while we focus on social distancing and support for lockdown policies, these are not the only measures that have been used to slow the spread of COVID-19, nor are they the only aspects of public health compliance (others include hand washing, mask wearing, etc.). Third, while we include a robust set of controls in addition to our various personality traits, we are unable to account for all possible alternative mechanisms such as fear, risk tolerance, anxiety, and others. Fourth, it is possible that our informational vignettes were not powerful enough to illicit more nuanced responses. Finally, while we draw on a large and fairly representative sample, it was generated from an online non-probability pool of respondents which may have implications for generalizability. Limitations aside, our results show that individual differences in personality are an important part of the puzzle for understanding who does and does not comply with public health guidelines for social distancing.

\section{DATA AVAILABILITY STATEMENT}

The raw data supporting the conclusions of this article will be made available by the authors, without undue reservation.

\section{ETHICS STATEMENT}

The studies involving human participants were reviewed and approved by Carleton University Research Ethics Board-B (CUREB-B). The patients/participants provided their informed consent to participate in this study.

\section{AUTHOR CONTRIBUTIONS}

JB and SP developed the survey instrument as part of a larger project and conceptualized the paper. All three authors developed the specific experimental manipulation from Part 2. JB and PC conducted data analyses. All three authors participated in writing separate sections of the paper and in editing the final draft.

\section{FUNDING}

This research was supported by a SSHRC Insight Development Grant (File \#: 430-2018-00950).

\section{SUPPLEMENTARY MATERIAL}

The Supplementary Material for this article can be found online at: https://www.frontiersin.org/articles/10.3389/fpos.2021.660911/ full\#supplementary-material 


\section{REFERENCES}

Agius, J., Webb, D., and Annett, E. (2020). How Many Coronavirus Cases Are There in Canada, by Province, and Worldwide? the Latest Maps and Charts. Globe and Mail. Available at: https://www.theglobeandmail.com/canada/ article-coronavirus-cases-canada-world-map-explainer/\#most-affectedcountriesnav (Accessed December 15, 2020).

Ashton, M. C., Lee, K., and de Vries, R. E. (2014). The HEXACO HonestyHumility, Agreeableness, and Emotionality Factors. Pers Soc. Psychol. Rev. 18, 139-152. doi:10.1177/1088868314523838

Ashton, M. C., and Lee, K. (2007). Empirical, Theoretical, and Practical Advantages of the HEXACO Model of Personality Structure. Pers Soc. Psychol. Rev. 11, 150-166. doi:10.1177/1088868306294907

Ashton, M., and Lee, K. (2009). The HEXACO-60: A Short Measure of the Major Dimensions of Personality. J. Personal. Assess. 91 (4), 340-345. doi:10.1080/ 00223890902935878

Ataguba, O. A., and Ataguba, J. E. (2020). Social determinants of health: The role of effective communication in the COVID-19 pandemic in developing countries. Global Health Action 13 (1), 1788263. doi:10.1080/16549716.2020.1788263

Banerjee, D., and Sathyanarayana Rao, T. (2020). Psychology of Misinformation and the media: Insights from the COVID-19 Pandemic. Indian J. Soc. Psychiatry 36 (5), 131. doi:10.4103/ijsp.ijsp_112_20

Bavel, J. J. V., Baicker, K., Boggio, P. S., Capraro, V., Cichocka, A., Cikara, M., et al. (2020). Using Social and Behavioural Science to Support COVID-19 Pandemic Response. Nat. Hum. Behav. 4, 460-471. doi:10.1038/s41562-020-0884-z

Bernhardt, J. M. (2004). Communication at the Core of Effective Public Health. Am. J. Public Health 94 (12), 2051-2053. doi:10.2105/AJPH.94.12.2051

Bilancini, E., Boncinelli, L., Capraro, V., Celadin, T., and Di Paolo, R. (2020). The Effect of Norm-Based Messages on reading and Understanding COVID-19 Pandemic Response Governmental Rules. Available at: https://psyarxiv.com/ 7863g (Accessed December 15, 2020).

Bogg, T., and Roberts, B. W. (2004). Conscientiousness and Health-Related Behaviors: A Meta-Analysis of the Leading Behavioral Contributors to Mortality. Psychol. Bull. 130, 887-919. doi:10.1037/0033-2909.130.6.887

Brouard, S., Vasilopoulos, P., and Becher, M. (2020). Sociodemographic and Psychological Correlates of Compliance with the COVID-19 Public Health Measures in France. Can. J. Pol. Sci. 53 (2), 253-258. doi:10.1017/ S0008423920000335

Byrne, B. M. (1994). Structural Equation Modeling with EQS and EQS/ Windows: Basic Concepts, Applications, and Programming. Thousand Oaks, CA: Sage.

Carvalho, L. D. F., Pianowski, G., and Gonçalves, A. P. (2020). Personality Differences and COVID-19: Are Extroversion and Conscientiousness Personality Traits Associated with Engagement with Containment Measures? Trends Psychiatry Psychother. 42 (2), 179-184. doi:10.1590/22376089-2020-0029

Caspi, A., and Moffitt, T. E. (1993). When Do Individual Differences Matter? A Paradoxical Theory of Personality Coherence. Psychol. Inq. 4 (4), 247-271. doi:10.1207/s15327965pli0404_1

CBC News (2021). Coronavirus: What's Happening in Canada and Around the World on April 22. Available at: https://www.cbc.ca/news/world/ coronavirus-covid19-canada-world-april22-2021-1.5997488 (Accessed May 1, 2021).

Chen, P., and Farhart, C. (2020). Gender, Benevolent Sexism, and Public Health Compliance. Pol. Gen. 16 (4), 1036-1043. doi:10.1017/s1743923x20000495

Chen, P., Pruysers, S., and Blais, J. (2020). The Dark Side of Politics: Participation and the Dark Triad. Polit. Stud.. doi:10.1177/0032321720911566

Chen, P. (2015). Taking Campaigns Personally: The Big Five Aspects and Political Behavior. Minneapolis: Retrieved from the University of Minnesota Digital Conservancy. Available at: http://hdl.handle.net/11299/175396 (Accessed December 15, 2020) doi:10.1109/bigdata.2015.7364115

Cheng, C., Barceló, J., Hartnett, A. S., Kubinec, R., and Messerschmidt, L. (2020). COVID-19 Government Response Event Dataset (CoronaNet v.1.0). Nat. Hum. Behav. 4, 756-768. doi:10.1038/s41562-020-0909-7

Clark, C., Davila, A., Regis, M., and Kraus, S. (2020). Predictors of COVID-19 Voluntary Compliance Behaviors: An International Investigation. Glob. transitions 2, 76-82. doi:10.1016/j.glt.2020.06.003
Collison, K. L., Vize, C. E., Miller, J. D., and Lynam, D. R. (2018). Development and Preliminary Validation of a Five Factor Model Measure of Machiavellianism. Psychol. Assess. 30 (10), 1401-1407. doi:10.1037/pas0000637

Costa, P. T., and McCrae, R. R. (1992). The Five-Factor Model of Personality and its Relevance to Personality Disorders. J. Personal. Disord. 6 (4), 343-359. doi:10.1521/pedi.1992.6.4.343

Crowe, M. L., Edershile, E. A., Wright, A. G. C., Campbell, W. K., Lynam, D. R., and Miller, J. D. (2018). Development and Validation of the Narcissistic Vulnerability Scale: An Adjective Rating Scale. Psychol. Assess. 30 (7), 978-983. doi:10.1037/pas0000578

Dubois, D., Rucker, D. D., and Galinsky, A. D. (2016). Dynamics of Communicator and Audience Power: The Persuasiveness of Competence versus Warmth. J. Consum Res. 43, 68-85. doi:10.1093/jcr/ucw006

Dunham, J. (2021). Canada Surpasses 1 Million Confirmed COVID-19 Cases since Start of Pandemic. Available at: https://www.ctvnews.ca/health/coronavirus/ canada-surpasses-1-million-confirmed-covid-19-cases-since-start-of-pandemic1.5373550 (Accessed May 1, 2021).

Everett, J. A., Colombatto, C., Chituc, V., Brady, W. J., and Crockett, M. (2020). The Effectiveness of Moral Messages on Public Health Behavioral Intentions during the COVID-19 Pandemic. Available at: https://psyarxiv.com/9yqs8 10.1287/ 5a3216f2-32c0-4b72-8bd1-993a3e8d8875 (Accessed December 15, 2020).

Farias, J., and Pilati, R. (2020). COVID-19 as an Undesirable Political Issue. Conspiracy Beliefs and Political Partisanship Predict Adhesion to Sanitary Measures. Pre-print available at: https://psyarxiv.com/97gn4/ (Accessed December 15, 2020)

Feldman, S., and Johnston, C. (2014). Understanding the Determinants of Political Ideology: Implications of Structural Complexity. Polit. Psychol. 35 (3), 337-358. doi:10.1111/pops.12055

Feng, B., and MacGeorge, E. L. (2006). Predicting Receptiveness to Advice: Characteristics of the Problem, the Advice-Giver, and the Recipient. South. Commun. J. 71 (1), 67-85. doi:10.1080/10417940500503548

Freimuth, V. S., and Quinn, S. C. (2004). The Contributions of Health Communication to Eliminating Health Disparities. Am. J. Public Health 94 (12), 2053-2055. doi:10.2105/AJPH.94.12.2053

Friedman, H. S., Kern, M. L., and Reynolds, C. A. (2010). Personality and Health, Subjective Well-Being, and Longevity. J. Personal. 78, 179-216. doi:10.1111/j. 1467-6494.2009.00613.x

Gollwitzer, M., Platzer, C., Zwarg, C., and Göritz, A. S. (2020). Public Acceptance of Covid-19 Lockdown Scenarios. Int. J. Psychol. doi:10.1002/ijop.12721

Goren, P., Federico, C. M., and Kittilson, M. C. (2009). Source Cues, Partisan Identities, and Political Value Expression. Am. J. Polit. Sci. 53, 805-820. doi:10. 1111/j.1540-5907.2009.00402.x

Government of Canada (2021). Mathematical Modelling and COVID-19. Available at: https://www.canada.ca/en/public-health/services/diseases/coronavirusdisease-covid-19/epidemiological-economic-research-data/mathematicalmodelling.html (Accessed May 1, 2021).

Götz, F. M., Gvirtz, A., Galinsky, A. D., and Jachimowicz, J. M. (2021). How Personality and Policy Predict Pandemic Behavior: Understanding ShelteringIn-Place in 55 Countries at the Onset of COVID-19. Am. Psychol. 76, 39-49. doi:10.1037/amp0000740

Harper, C. A., Satchell, L. P., Fido, D., and Latzman, R. D. (2020). Functional Fear Predicts Public Health Compliance in the COVID-19 Pandemic. Int. J. Ment. Health Addict., 1-14. doi:10.1007/s11469-020-00281-5

Hirsh, J. B., Kang, S. K., and Bodenhausen, G. V. (2012). Personalized Persuasion: Tailoring Persuasive Appeals to Recipients' Personality Traits. Psychol. Sci. 23 (6), 578-581. doi:10.4324/9781843145073

Hodson, J. (2020). Why Young People Tune Out of Government COVID-19 Messaging. The Conversation. Available at: https://theconversation.com/whyyoung-people-tune-out-government-covid-19-messaging-147817 (Accessed May 1, 2021).

Holland, S., and Mason, J. (2020). Trump Warns Americans of a Tough Two Weeks Ahead in Coronavirus Fight. Reuters. Available at: https://www. reuters.com/article/us-health-coronavirus-trump/trump-warns-americansof-a-tough-two-weeks-ahead-in-coronavirus-fight-idUSKBN21I3HK doi:10. $7765 / 9781526134226$

Inglehart, R. F. (1997). Modernization and Postmodernization: Cultural, Economic, and Political Change in 43 Societies. Princeton, NJ: Princeton University Press. doi:10.1515/9780691214429 
Iyengar, S. (1990). Framing Responsibility for Political Issues: The Case of Poverty. Polit. Behav. 12 (1), 19-40. doi:10.1007/bf00992330

Jay, J., Bor, J., Nsoesie, E. O., Lipson, S. K., Jones, D. K., Galea, S., et al. (2020). Neighbourhood Income and Physical Distancing During The COVID-19 Pandemic in The United States. Nature Human Behav. 4, 1294-1302. doi:10.1038/s41562-020-00998-2

Jordan, J., Yoeli, E., and Rand, D. (2020). Don't Get it or Don't Spread it? Comparing Self-Interested versus Prosocially Framed COVID-19 Prevention Messaging. Available at: https://psyarxiv.com/yuq7x/ (Accessed May 1, 2021).

Judge, T. A., Heller, D., and Mount, M. K. (2002). Five-factor Model of Personality and Job Satisfaction: A Meta-Analysis. J. Appl. Psychol. 87 (3), 530-541. doi:10. 1037/0021-9010.87.3.530

Kemp, E., Bui, M., and Porter, M., III (2021). Preparing for a Crisis: Examining the Influence of Fear and Anxiety on Consumption and Compliance. J. Consumer Marketing 38 (3), 282-292. doi:10.1108/JCM-05-2020-3841

Koisinki, M., Stillwell, D., and Graepel, T. (2013). Private Traits and Attributes Are Predictable from Digital Records of Human Behavior. PNAS 110 (15), 5802-5805. doi:10.1073/pnas.1218772110

Larsen, R. J., Buss, D. M., King, D. B., and Ensley, C. E. (2018). Personality Psychology: Domains of Knowledge about Human Nature. Toronto: McGrawHill.

Laustsen, L., and Petersen, M. B. (2016). Winning Faces Vary by Ideology: How Nonverbal Source Cues Influence Election and Communication Success in Politics. Polit. Commun. 33 (2), 188-211. doi:10.1080/10584609.2015. 1050565

Lavine, H., and Snyder, M. (1996). Cognitive Processing and the Functional Matching Effect in Persuasion: The Mediating Role of Subjective Perceptions of Message Quality. J. Exp. Soc. Psychol. 32 (6), 580-604. doi:10. 1006/jesp.1996.0026

Lee, K., and Ashton, M. C. (2018). Psychometric Properties of the HEXACO-100. Assessment 25, 543-556. doi:10.1177/1073191116659134

Makridis, C. A., and Wu, C. (2021). How Social Capital Helps Communities Weather the COVID-19 Pandemic. PLOS One 16 (1), e0245135. doi:10.1371/ journal.pone. 0245135

Malouff, J. M., Thorsteinsson, E. B., Schutte, N. S., Bhullar, N., and Rooke, S. E. (2010). The Five-Factor Model of Personality and Relationship Satisfaction of Intimate Partners: A Meta-Analysis. J. Res. Personal. 44 (1), 124-127. doi:10. 1016/j.jrp.2009.09.004

Matz, S. C., Kosinski, M., Nave, G., and Stillwell, D. J. (2017). Psychological Targeting as an Effective Approach to Digital Mass Persuasion. Proc. Natl. Acad. Sci. USA 114 (48), 12714-12719. doi:10.1073/pnas.1710966114

Melki, J., Tamim, H., Hadid, D., Farhat, S., Makki, M., Ghandour, L., et al. (2020). Media Exposure and Health Behavior during Pandemics: The Mediating Effect of Perceived Knowledge and Fear on Compliance with COVID-19 Prevention Measures. Health Commun. 1-11. doi:10.1080/10410236.2020.1858564

Merkley, E., Bridgman, A., Loewen, P. J., Owen, T., Ruths, D., and Zhilin, O. (2020). A Rare Moment of Cross-Partisan Consensus: Elite and Public Response to the COVID-19 Pandemic in Canada. Can. J. Pol. Sci. 53 (2), 311-318. doi:10.1017/ S0008423920000311

Mevorach, T., Cohen, J., and Apter, A. (2021). Keep Calm and Stay Safe: The Relationship between Anxiety and Other Psychological Factors, media Exposure and Compliance with COVID-19 Regulations. Ijerph 18 (6), 2852. doi:10.3390/ijerph18062852

Miguel, F. K., Machado, G. M., Pianowski, G., and Carvalho, L. F. (2020). Compliance with Containment Measures to the COVID-19 Pandemic over Time: Do Antisocial Traits Matter? Pers Individ Dif 168, 110346. doi:10.1016/j. paid.2020.110346

Miller, J. D., Hyatt, C. S., Maples-Keller, J. L., Carter, N. T., and Lynam, D. R. (2017). Psychopathy and Machiavellianism: A Distinction without a Difference? J. Pers 85 (4), 439-453. doi:10.1111/jopy.12251

Miller, J. D., Vize, C., Crowe, M. L., and Lynam, D. R. (2019). A Critical Appraisal of the Dark-Triad Literature and Suggestions for Moving Forward. Curr. Dir. Psychol. Sci. 28 (4), 353-360. doi:10.1177/0963721419838233

Miller, J., and Krosnick, J. (1997). "Anatomy of News media Priming," in Do the media Govern. Editors S. Iyengar and R. Reeves (Thousand Oaks: Sage Publications).

Mondak, J. (2010). Personality and the Foundations of Political Behavior. New York: Cambridge University Press. doi:10.1017/cbo9780511761515
Moon, Y. (2002). Personalization and Personality: Some Effects of Customizing Message Style Based on Consumer Personality. J. Consumer Psychol. 12 (4), 313-326. doi:10.1207/s15327663jcp1204_04

Mordecai, M. (2020). How People Around the World See the World Health Organization's Initial Coronavirus Response. PEW Research Centre. Available at: https://www.pewresearch.org/fact-tank/2020/11/12/how-peoplearound-the-world-see-the-world-health-organizations-initial-coronavirusresponse/.

Motta, M., Callaghan, T., and Sylvester, S. (2018). Knowing Less but Presuming More: Dunning-Kruger Effects and the Endorsement of Anti-vaccine Policy Attitudes. Soc. Sci. Med. 211, 274-281. doi:10.1016/j.socscimed.2018.06.032

Motta, M., Stecula, D., and Farhart, C. (2020). How Right-Leaning media Coverage of COVID-19 Facilitated the Spread of Misinformation in the Early Stages of the Pandemic in the US. Can. J. Polit. Science/Revue Canadienne de Sci. Politique 53 (2), 335-342. doi:10.1017/s0008423920000396

Nowak, B., Brzóska, P., Piotrowski, J., Sedikides, C., Żemojtel-Piotrowska, M., and Jonason, P. K. (2020). Adaptive and Maladaptive Behavior during the COVID19 Pandemic: The Roles of Dark Triad Traits, Collective Narcissism, and Health Beliefs. Pers. Individ. Differ. 167, 110232. doi:10.1016/j.paid.2020.110232

O'Connell, K., Berluti, K., Rhoads, S. A., and Marsh, A. A. (2021). Reduced Social Distancing Early in the COVID-19 Pandemic Is Associated with Antisocial Behaviors in an Online United States Sample. PLoS ONE 16 (1), e0244974. doi:10.1371/journal.pone.0244974

Osborne, D., Satherley, N., and Sibley, C. G. (2020). "Personality and Ideology: A Meta-Analysis of the Reliable, but Non-causal, Association between Openness and Conservatism," in The Oxford Handbook of Behavioral Political Science. Editors A. Mintz and L. Terris (New York: Oxford University Press).

Osborne, D., and Sibley, C. G. (2012). Does Personality Matter? Openness Correlates with Vote Choice, but Particularly for Politically Sophisticated Voters. J. Res. Personal. 46 (6), 743-751. doi:10.1016/j.jrp.2012.09.001

Painter, M., and Qiu, T. (2020). Political Beliefs Affect Compliance with COVID19 Social Distancing Orders (July 3, 2020). Available at: SSRN: https://ssrn.com/ abstract $=3569098$ (Accessed December 15, 2020). doi:10.2139/ssrn.3569098

Paulhus, D. L., Neumann, C. S., and Hare, R. D. (2016). Manual for the SelfReported Psychopathy Scale 4th Ed. Toronto: Multi-Health Systems.

Paulhus, D. L., and Williams, K. M. (2002). The Dark Triad of Personality: Narcissism, Machiavellianism, and Psychopathy. J. Res. Personal. 36 (6), 556-563. doi:10.1016/S0092-6566(02)00505-6

Pickup, M., Stecula, D., and Van der Linden, C. (2020). Novel Coronavirus, Old Partisanship: COVID-19 Attitudes and Behaviours in the United States and Canada. Can. J. Pol. Sci. 53 (2), 357-364. doi:10.1017/S0008423920000463

Pitas, N., and Ehmer, C. (2020). Social Capital in the Response to COVID-19. Am. J. Health Promot. 34 (8), 942-944. doi:10.1177/0890117120924531

Plohl, N., and Musil, B. (2020). Modeling Compliance with COVID-19 Prevention Guidelines: the Critical Role of Trust in Science. Psychol. Health Med. 26, 1-12. doi:10.1080/13548506.2020.1772988

Qian, K., and Yahara, T. (2020). Mentality and Behavior in COVID-19 Emergency Status in Japan: Influence of Personality, Morality and Ideology. PLoS One 15 (7), e0235883. doi:10.1371/journal.pone.0235883

Roma, P., Monaro, M., Muzi, L., Colasanti, M., Ricci, E., Biondi, S., et al. (2020). How to Improve Compliance with Protective Health Measures during the COVID-19 Outbreak: Testing a Moderated Mediation Model and Machine Learning Algorithms. Int. J. Environ. Res. Public. Health 17 (19), 7252. doi:10. 3390/ijerph17197252

Rosenthal, S. A., Hooley, J. M., Montoya, R. M., van der Linden, S. L., and Steshenko, Y. (2020). The Narcissistic Grandiosity Scale: A Measure to Distinguish Narcissistic Grandiosity from High Self-Esteem. Assessment 27 (3), 487-507. doi:10.1177/1073191119858410

Sevi, S., Aviña, M. M., Péloquin-Skulski, G., Heisbourg, E., Vegas, P., Coulombe, M., et al. (2020). Logarithmic versus Linear Visualizations of COVID-19 Cases Do Not Affect Citizens' Support for Confinement. Can. J. Pol. Sci. 53, 385-390. doi:10.1017/s000842392000030x

Sibley, C. G., Osborne, D., and Duckitt, J. (2012). Personality and Political Orientation: Meta-Analysis and Test of a Threat-Constraint Model. J. Res. Personal. 46 (6), 664-677. doi:10.1016/j.jrp.2012.08.002

Sleep, C. E., Lynam, D. R., Hyatt, C. S., and Miller, J. D. (2017). Perils of Partialing Redux: The Case of the Dark Triad. J. Abnormal Psychol. 126 (7), 939-950. doi:10.1037/abn0000278 
Utych, S., and Fowler, L. (2020). More Human Than Human: The Consequences of Positive Dehumanization. Administrative Theor. Praxis 3 (1), 1-19. doi:10. 1080/10841806.2020.1829258

van der Meer, T. W. G., van Deth, J. W., and Scheepers, P. L. H. (2009). The Politicized Participant. Comp. Polit. Stud. 42 (11), 1426-1457. doi:10.1177/0010414009332136

Williams, K. M., Paulhus, D. L., and Hare, R. D. (2007). Capturing the Four-Factor Structure of Psychopathy in College Students via Self-Report. J. Personal. Assess. 88 (2), 205-219. doi:10.1080/00223890701268074

World Health Organization (2020). WHO Director-General's Opening Remarks at the media Briefing on COVID-19 - 11 March 2020. Available at: https://www. who.int/director-general/speeches/detail/who-director-general-s-openingremarks-at-the-media-briefing-on-covid-19-11-march-2020\#: :text=We\% 20have\%20therefore $\% 20$ made $\% 20$ the,to\%20unnecessary\%20suffering\%20and\% 20death (Accessed December 15, 2020).

Wright, L., Steptoe, A., and Fancourt, D. (2020). What Predicts Adherence to COVID-19 Government Guidelines? Longitudinal Analyses of 51,000 UK Adults. Available at: https://www.medrxiv.org/content/10.1101/2020.10.19. 20215376v1 (Accessed December 15, 2020). doi:10.1101/2020.10.19.20215376
Wu, C. (2021). Social Capital and COVID-19: A Multidimensional and Multilevel Approach. Chin. Sociol. Rev. 53 (1), 27-54. doi:10.1080/21620555.2020. 1814139

Zajenkowski, M., Jonason, P. K., Leniarska, M., and Kozakiewicz, Z. (2020). Who Complies with the Restrictions to Reduce the Spread of COVID-19? Personality and perceptions of the COVID-19 situation. Pers. Individ. Differ. 166, 110199. doi:10.1016/j.paid.2020.110199

Conflict of Interest: The authors declare that the research was conducted in the absence of any commercial or financial relationships that could be construed as a potential conflict of interest.

Copyright (c) 2021 Blais, Chen and Pruysers. This is an open-access article distributed under the terms of the Creative Commons Attribution License (CC BY). The use, distribution or reproduction in other forums is permitted, provided the original author(s) and the copyright owner(s) are credited and that the original publication in this journal is cited, in accordance with accepted academic practice. No use, distribution or reproduction is permitted which does not comply with these terms. 